\title{
Possible Anisakiasis Associated with Fishery Resumption
}

\author{
Yoshitaka Nishikawa, MD; Masaharu Tsubokura, MD; Shigeaki Kato, PhD; \\ Yasutoshi Saito, MD, PhD
}

A 63-year-old woman with severe upper abdominal pain arrived at our hospital in Soma City, Fukushima prefecture. An immediate endoscopy showed Anisakis simplex larva on a local mucosal edematous lesion, with oozing blood at the inferior border of the greater curvature of the stomach (Figure 1). Removal of the parasite with the use of biopsy forceps completely relieved the patient's symptoms. Her medical history disclosed that 8 hours before the onset of pain the patient ingested raw squid and mackerel, which were assumed to convey the larva.

Before the Great East Japan Earthquake disaster, Soma City was a leading fishing port in the northeastern region of Japan, with an abundance of flatfish, squid, and octopus. However, a meltdown of the reactors at the Fukushima Daiichi nuclear power plant occurred following the 2011 earthquake and subsequent tsunami. The ensuing release of radioactive material into the air, water, and soil raised serious health concerns for nearby residents.

Radionuclides in fish and other seafood products have been monitored since March 23, 2011, ${ }^{1}$ in conjunction with the screening of internal radiation exposure for

\section{FIGURE 1}

\section{Anisakis simplex Larva on Local Mucosal Edematous Lesion Was Observed by Endoscopy.}

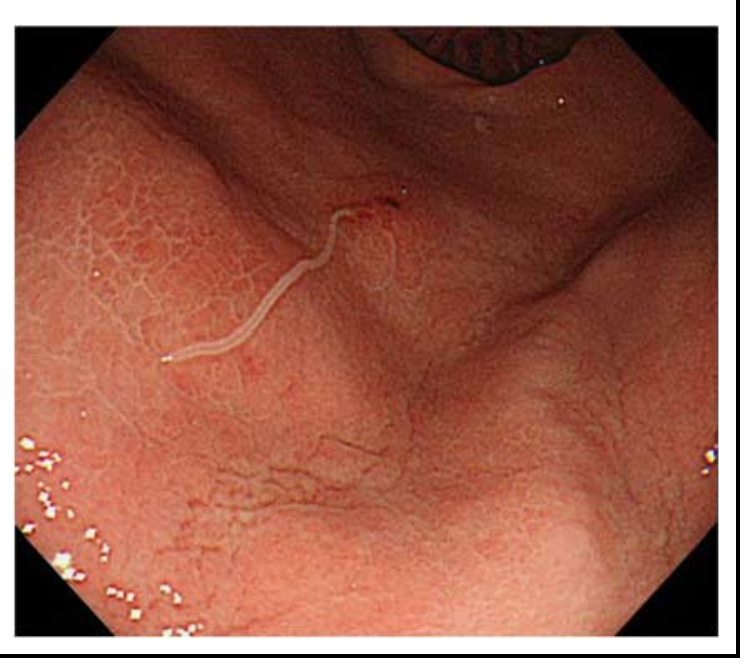

residents in the affected area. ${ }^{2}$ The local fishery in Soma City voluntarily banned fishing in the radiation-contaminated sea immediately after the disaster. $^{3}$ A search for radiation by the fisheries experimental station found radionuclide levels in the fish of Fukushima to be highly variable. ${ }^{1}$

Beginning in June 2012, limited fishing was gradually resumed (Figure 2). Because the residents in this area were previously accustomed to a diet of raw fish, they were more likely to resume that same dietary pattern soon after the resumption of fishing, leading to higher risks of parasitization, as occurred before the disaster. This case was the first case suggesting a clinical association with fishery resumption in our hospital. Because anisakiasis has been reported, especially in coastal regions, with frequent ingestion of fish, ${ }^{4}$ the symptoms described here may represent a medical indicator of recovery from the disaster in this region.

We believe that the current findings provide a positive association between recovery from the disaster and exposure to Anisakis simplex, whereas the inverse relationship between the disaster recovery and development of chronic disease had been previously reported. ${ }^{5}$ Medical providers should thus be aware of renewed cases of anisakiasis after the resumption of

\section{FIGURE 2}

\section{Limited Fishing in Fukushima Resumed in June 2012.}

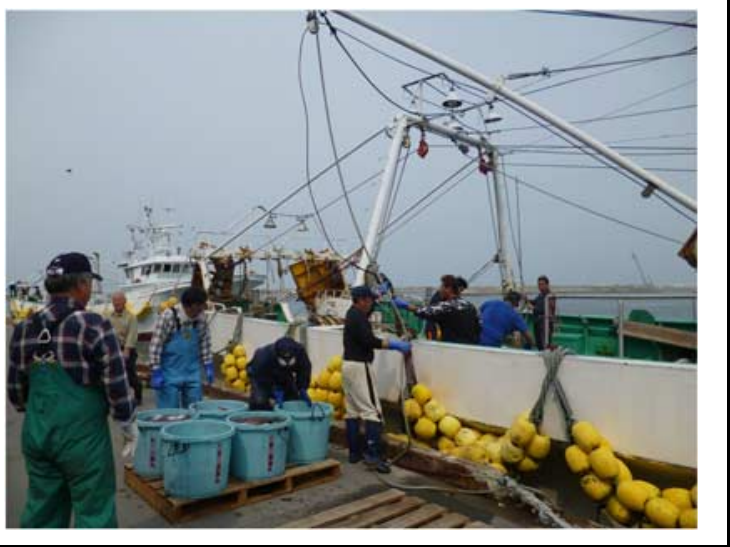


fishing in the affected coastal areas by the Fukushima Nuclear plant and in other areas similarly affected.

\section{About the Authors}

Departments of Internal Medicine (Drs Nishikawa and Saito) and Radiation Protection (Drs Tsubokura and Kato), Soma Central Hospital, Fukushima; and Division of Social Communication System for Advanced Clinical Research, Institute of Medical Science, University of Tokyo (Dr Tsubokura), Tokyo, Japan.

Correspondence and reprint requests to Yasutoshi Saito, MD, PhD, Department of Internal Medicine, Soma Central Hospital, Okinouchi, Soma City, Fukushima, 976-0016, Japan (e-mail: y-saitou@tachiya.or.jp).

\section{Acknowledgment}

Soma-Futaba Fisheries provided information for the preparation of this report.

Published online: April 3, 2014.

\section{REFERENCES}

1. Fisheries Agency. Results of the inspection on radioactivity materials in fisheries products. Tokyo, Japan: Ministry of Agriculture, Forestry and Fisheries; 2013. http://www.jfa.maff.go.jp/e/inspection/index.html. Accessed October 29, 2013.

2. Tsubokura M, Gilmour S, Takahashi K, Oikawa T, Kanazawa Y. Internal radiation exposure after the Fukushima nuclear power plant disaster. JAMA. 2012;308:669-670.

3. Buesseler KO. Ecology: fishing for answers off Fukushima. Science. 2012; 338:480-482.

4. Hochberg NS, Hamer DH. Anisakidosis: Perils of the deep. Clin Infect Dis. 2010;51:806-812.

5. Tsubokura M, Takita M, Matsumura T, et al. Changes in metabolic profiles after the Great East Japan Earthquake: a retrospective observational study. BMC Public Health. 2013;13:267, 2458-2413-267. 